\title{
EL LENGUAJE COMO HERMENÉUTICA EN LA COMPRENSIÓN DEL PASADO: A PROPÓSITO DEL PUQUINA EN LA GÉNESIS DEL IMPERIO INCAICO
}

\author{
LANGUAGE AS HERMENEUTICS IN THE COMPREHENSION OF THE PAST: \\ IN PURPOSE OF PUQUINA IN THE GENESIS OF THE INCA EMPIRE
}

\author{
Rodolfo Cerrón-Palomino*
}

\begin{abstract}
En el presente estudio se aportan evidencias lingüístico-filológicas que demuestran la filiación puquina del léxico cultural-institucional y religioso del incario, demostrando la procedencia altiplánica de esta civilización.

Palabras claves: Hermenéutica, etimología, filología, cuzco-centrismo, aimarismo primitivo, quechuismo primitivo, puquinización, protoquechua.
\end{abstract}

In this contribution, linguistic-philological evidences are presented, which show the provenance of an important amount of the cultural-institutional and religious lexicon of the Incas from the Puquina language, thereby showing the Altiplano origin of this civilization.

Key words: Hermeneutics, etymology, philology, Cuzco-centrism, primeval Aymarism, primeval Quechuism, Puquinization, proto-Quechua.

\section{Introducción}

\begin{abstract}
La hermenéutica es el arte de interpretar los textos en un contexto distinto al de su autor y al de su auditorio inicial, con el afán de descubrir nuevas dimensiones de la realidad.
\end{abstract}

Ricoeur (1986:155)

Salvo honrosas excepciones, la invocación del enfoque interdisciplinario para dar cuenta y razón de los hechos del pasado andino ha tenido un sesgo marcado: la exclusión, consciente o inconsciente, de la lingüística histórica y de la filología. Cuando mucho, la información lingüística manejada por historiadores y arqueólogos corresponde a la vieja práctica decimonónica, como si la disciplina se hubiese estancado en su etapa precientífica. Como resultado de ello se han venido construyendo hipótesis acerca de la estructura y la organización social, espacial y simbólica de los pueblos prehispánicos a base del manejo arbitrario y errático, cuando no deliberadamente distorsionado, del léxico institucional y cultural registrado en lexicones, gramáticas y crónicas, al margen del examen filológico y riguroso mínimos que la consulta de tales fuentes exige. En la ponencia se ofrecerán algunos ejemplos que ilustran dicha práctica en nuestro medio dando lugar a esquemas interpretativos del pasado andino construidos sobre bases deleznables y antojadizas.

\section{Cuestiones generales}

Como sabemos, los cronistas filtran toda la información acerca de los incas por medio del quechua, que entonces era lo que podríamos llamar la "lengua oficial" del imperio. Es en tal contexto en el que hay que entender el rol de los primeros lenguaraces quechuas, quienes se constituyen desde muy temprano en peritos "oficiales" en cuestiones relativas a la lengua general y, por consiguiente, a la cultura vehiculizada por ella (los casos de Betanzos y de Molina, por citar los más conocidos, resultan ejemplares), dejando de lado a los expertos en aimara, la otra lengua general igualmente importante por entonces. El Inca Garcilaso será el exponente máximo de esta tendencia, aun cuando, en verdad, su quechua será diferente del que hablaba la casta imperial hasta por lo menos el genocidio cometido con ella por las huestes de Atahualpa, y del que nos han dejado muestras los cronistas más tempranos como los mencionados (ver Cerrón-Palomino 2013a,

\footnotetext{
* Pontificia Universidad Católica del Perú. Lima, Perú. Correo electrónico: rcerron@pucp.pe
} 
III-14: § 4). La historiografía incaica hereda esta corriente del "quechuismo primitivo", según la frase acuñada por Raúl Porras, desde el siglo XVI en adelante, manteniéndose vigente entre la mayoría de los etnohistoriadores modernos del área andina. A fines del siglo XIX y comienzos del XX surge, como una contracorriente, la tesis del "aimarismo primitivo" (encarnada en Middendorf y Uhle), aceptada tímidamente por los historiadores de la civilización incaica (Zuidema, Rostworowski, Szemiñski), sin descartar la corriente canónica del quechuismo primitivo.

\section{La lingüística histórica quechua: desmitificación y nuevos planteamientos}

Los estudios del quechua dan un vuelco rotundo en sus planteamientos, hasta entonces cautivos dentro de una visión cuzcocéntrica, en la segunda mitad del siglo XX, con los trabajos revolucionarios de Parker (2013, I [1963]) y de Torero (1964), demostrando que el quechua no podía haberse originado en el Cuzco sino en la sierra centroandina. Algún tiempo después se sostendrá, en relación con la segunda lengua general del antiguo Perú, que su cuna original no sería el altiplano sino la costa y sierra centroandinas (Hardman 1975 [1966], Torero 1972, CerrónPalomino 2000).

Las consecuencias deducibles de tales planteamientos, apoyados en los trabajos de lingüística histórica y filología que fueron sucediéndose, pueden resumirse en los siguientes puntos: (a) que los incas hablaban aimara hasta el siglo XV e hicieron sus "cortes" en el centro del mundo considerado como el "Taipi Cala", es decir, el "El hito central de piedra", o sea, Tiahuanaco (ver Szemiñski 2003); (b) que la "lengua oficial" de los incas históricos fue la aimara y no la quechua (ver Cerrón-Palomino 2013a:II$6,7,8,9$ ); (c) que en el altiplano se hablaban el puquina, la lengua de Tiahuanaco, y el uro (Torero 1987, Cerrón-Palomino 2006), antes que el aimara; (d) que los incas míticos, procedentes del Titicaca, hablaban la lengua tiahuanacota (Cerrón-Palomino 2013a; I-2:3); (e) que el "lenguaje particular" de que nos hablan el Inca Garcilaso y otros cronistas habría sido una variedad de aimara puquinizada (Cerrón-Palomino 2013a;I-2); y (d) que por "collas" hay que entender "puquina-collas", de habla puquina, y no pueblos de parla aimara (Julien 1983; Bouysse-Cassagne 1988; Torero 1987).

\section{El puquina en la génesis y desarrollo del imperio incaico}

En la sección que sigue ofreceremos, como demostración de lo señalado en $\S 2$, la filiación puquina de seis categorías de nombres que, de acuerdo con la tesis del "quechuismo primitivo", han sido considerados tradicionalmente como de procedencia quechua. Tales nombres han sido agrupados bajo los siguientes rubros: (a) de divinidades, (b) de personajes míticos, (c) de epítetos reales, (d) de incas, (e) instituciones, y (f) topónimos.

\section{Nombres de divinidades}

Tres son las designaciones examinadas en esta sección, a saber: $<$ Contiti $>,<$ Viracocha $>$ e $<$ Inti $>$. Seguidamente nos ocuparemos de la etimología de cada una de ellas.

\section{Contiti}

Como se sabe, es el nombre de la divinidad preincaica que en tiempos del incario se empleaba básicamente como "sobrenombre" de $<$ viracocha>, seguramente al haberse oscurecido su significado inicial, según puede inferirse a partir de la expresión <contiti viracocha>, el dios "que hizo el mundo", consignada tempranamente por Betanzos (2015;I,I:fol. 3v;I,II:fol. 4v [1551]). Precisamente la opacidad total del nombre, que devino en simple epíteto, dio lugar a que los quechuistas de la época comenzaran a asociar el parcial <titi> de la designación con la voz quechua $<$ ticçi> (proveniente del protoquechua *tiq $s ̧ i$ “origen, principio, fundamento"), cosa que ya puede verse en el mismo Betanzos, que también registra <ticçi viracocha> (ver 2015:II,XXII:fol. 133r [1551]). De esta manera, en virtud de su quechuización parcial, la expresión resultaba más "comprensible", aun cuando quedara el remanente $<$ con> sujeto a mil conjeturas, sin posibilidades de ser interpretado a partir de la lengua. Lo que debe quedar claro, sin embargo, es que $<$ titi $>$ y $<$ ticçi> son radicales diferentes, irreductibles el uno al otro, y de filiación igualmente ajenas. En efecto, en otro lugar hemos ofrecido la etimología puquina del nombre < contiti> a partir de *q'utñi titi "Sol ardiente". Tendríamos de esta manera una designación de los antiguos puquina-collas de la divinidad creadora con atributos astrales, es 
decir, "una colaescencia del ser supremo con el dios solar" (ver Eliade 2000;III:224), cuyo culto le habría sido arrebatado más tarde por los incas. Para la etimología propuesta, ver Cerrón-Palomino (2013a;I-5) y las referencias proporcionadas allí.

\section{Viracocha}

En cuanto a este nombre, si bien aparentaba una fisonomía fónica quechua, semánticamente resultaba oscuro, y, por consiguiente, estaba sujeto a interpretaciones absurdas, como aquella famosa de "mar de sebo", que lamentablemente sigue encandilando a quienes prefieren seguir comulgando de la tesis del "quechuismo primitivo". En verdad, igual de oscura era tal designación que, para usarla, se hacía necesaria una aclaración en la forma de aposición, según se puede apreciar en la expresión cumulativa <contiti viracocha pachayachachic> "Dios hazedor del mundo", que registra Betanzos (ver 2015;I,II:4v;I,VII:1 1v;II,XVII:121;II,XXII:137 [1551]), donde por $<$ pachayachachic $>$ debe entenderse literalmente "el que hace morar el mundo" y no "el enseñador del mundo", como sostenía erróneamente el Inca Garcilaso (1943;II,II:68 [1609]). Este mismo historiador, sin embargo, tenía toda la razón al decir, respecto de $<$ viracocha $>$, que se trataba de un nombre primitivo e inanalizable, por lo que debía imputarse toda interpretación forzada de los supuestos componentes de la palabra, que descartaba como forma compuesta (ver Betanzos 2015;V,XXI:269 [1551]). Pues bien, en el presente caso postulamos una etimología aimara para el nombre que provendría de *wila quta, "lago de sangre", expresión metonímica que hacía referencia a la divinidad lacustre (el mismo <Contiti>), a quien los incas le ofrendaban la sangre de cientos de niños sacrificados, según las referencias obtenidas por el cronista de la virgen de Copacabana (ver Ramos Gavilán 1988;I,XVI:108 [1621]). Ocurre en este caso que los expertos de la lengua quechua de entonces, ante el enigma que suscitaba la expresión compuesta de $<$ vila-cota $>$, procedieron con la quechuización formal de esta, previo análisis intuitivo del vocablo, reacuñándola como $<$ vira-cocha $>$, cambiando el significado de $<$ vila $>$ "sangre" por < vira > "grasa", al mismo tiempo que la tornaban en un sinsentido, que motivaría en adelante las elucubraciones semánticas que se han venido proponiendo desde entonces. Como se puede apreciar, la etimología popular fue la responsable de la opacidad formal y semántica del nombre. Para la interpretación de < viracocha $>$, en los términos resumidos aquí, ver Cerrón-Palomino (2013a;II-12).

\section{Inti}

Por lo que respecta a esta palabra, no es difícil demostrar que se trata de un nombre extraño al quechua y al aimara, ya que tenemos evidencia que apoya nuestro aserto. En el primer caso, hay que señalar que la voz para "sol" era $<$ punchao $>$, tal como lo registran los cronistas, entre ellos Molina (2010:fol.26 [1573]). Esta palabra provenía del PQ *pun-ĉaw, "centro del día" (es decir, zenit), y hacía alusión al día solar, y por extensión a la divinidad andina, cuyo culto inicial era propio de los puquina-collas, como se mencionó. En el caso del aimara, no hay duda de que la voz que designaba al astro solar, y por extensión a la divinidad astral, era <villca> "el sol como antiguamente dezian, y agora dizen inti”, según señala Bertonio (ver 1984;II:386 [1612]), y que luego pasa a significar "adoratorio dedicado al Sol, o a otros ídolos" (ibídem). No es gratuito sostener entonces que, al igual que lo ocurrido en el aimara, la voz < punchaw > para designar al Sol, y de cuyo uso nos han dejado testimonio los cronistas, haya sido reemplazada por <inti>, voz que se generaliza posteriormente en todo el universo andino, y de cuyo uso en el puquina nos da testimonio Oré (1607:109). La pregunta tiene que ver entonces con el origen de esta palabra, que, aunque registrada en casi todos los dialectos quechuas, no parece remontar al PQ. De otro lado, no se requiere mucha perspicacia, ayudados por su forma y significado, para asociar la voz anti "oriente" con la que nos ocupa: después de todo, el sol nace en el oriente. Es más, tampoco resulta descabellado traer a cuento aquí la palabra mapuche <antui> "sol, día", que se sabe que no es un préstamo quechua, pero que obviamente está relacionada con las voces mencionadas. Las vicisitudes por las que han atravesado las vocales de tales términos podrían atribuirse al hecho de que tanto el puquina (ver de la Grasserie 1894) como el mapuche (ver Croesse 1989) parecen acusar relaciones genéticas distantes con las lenguas arahuacas de las que se habrían tomado. Para más datos acerca del tema, ver Cerrón-Palomino (2013a;I-2:§6.1.2,70-71). 


\section{Nombres de personajes míticos}

Como nombres propios de los personajes legendarios que marchan en dirección del valle del Cuzco hemos tomado los de los hermanos <Ayar $>$ (para la etimología de este nombre, ver Cerrón-Palomino 2013a;I-3:\$3.1.1), liderados por <Manco $>$, el jefe de la comitiva.

\section{Manco}

Comenzando por el nombre del caudillo del séquito de procedencia altiplánica, el de $<$ Manco $>$, incomprensible en el quechua e inexistente en el aimara, fuera de su registro como apelativo del fundador del Cuzco y de algunos miembros de su descendencia, fue sin embargo asociado por Uhle (1969:45 [1910]) con la voz aimara <mayco> "jefe de vasallos"; pero también, esta vez por Riva Agüero (1966:140 [1930]), con <mallku> "pichón de ave", o alternativamente con $<$ marku $>$ "artemisa", voces ambas de procedencia quechua. Descartadas estas últimas por razones de plausibilidad formal y semántica, quedaba como buen candidato el étimo postulado por el filólogo germano, quien se habría basado en Bertonio para sostenerlo. En efecto, el ilustre aimarista consigna en su vocabulario $<$ mayco>, "señor de vasallos", proporcionándonos al mismo tiempo el dato oportuno de que en "otros pueblos dizen Mallco" (ver Bertonio 1984;II:212, 220 [1612]). La variación fonética sugerida por el lexicógrafo no debe sorprender desde el momento en que $/ 11 / \mathrm{y} / \mathrm{y} /$ son consonantes palatales, y como tales, proclives a fluctuar en las lenguas andinas. Ahora bien, ocurre que los textos pastorales del puquina registraban también una voz parecida: nos referimos a $<$ macu $>$, "cacique o principal del ayllu" (ver Oré 1607:172). Esta forma es, a todas luces, una variante aimarizada de $<$ mayco $>$, con pérdida de $/ y /$ ante consonante, según regla conocida del aimara (ver Cerrón-Palomino 2000;V:§ 1.72). La pregunta que tenemos que hacernos ahora concierne a la relación genética que puedan tener las tres variantes mencionadas con el nombre propio $<$ Manco $>$. Aquí también conviene aclarar que esta forma puede explicarse como otra variante de $<$ mallco $>$, desde el momento en que la fluctuación $/ 11 / \sim / \tilde{n} /$ (y esta última con $/ \mathrm{n} /$ en posición de sílaba trabada) es igualmente frecuente en las lenguas andinas. Sumando hasta aquí las consideraciones formuladas previamente estamos en condiciones de postular *mallqu (pronunciado tal vez como [mañqo]) como el arquetipo puquina del nombre, a partir del que pueden explicarse, como variantes de un préstamo, las alternancias léxicas mencionadas. Para mayores detalles respecto de la etimología propuesta, véase Cerrón-Palomino (2013b;V:\$3.1.2).

Ayar

En cuanto a los tres hermanos restantes de Manco, todos hemos aprendido que fueron $<$ Ayar Auca $>$, <Ayar Cachi > y < Ayar Uchu $>$, los mismos que portarían nombres que harían alusión, en forma alegórica, al "progenitor guerrero" (awqa), al "ancestro de la sal" (kachi) y al "antepasado del ají" (uchu), respectivamente. Los manuales escolares, las enciclopedias, e incluso los tratados de corte académico no hacen sino perpetuar este saber establecido (ver, para citar los más recientes, Urbano 1981;XLIX; Rostworowski 1993:241245; Urton 1990;cap. 2:33; D’Altroy 2015;cap. $3: 71$ ). No hace falta estar muy familiarizados con el vocabulario quechua para darse cuenta de que aquí estamos ante un caso típico de interpretación sesgada de nombres arcanos a partir de la lengua que se asume es la fuente de los mismos. Dicha lectura ilusoria requirió, como ocurre en tales casos, del estrujamiento formal previo de los mismos, recubriéndolos de un velo fónico quechua. Porque, hay que señalarlo, las fuentes no muestran igual registro para tales nombres, y no necesariamente debido a problemas codicológicos de edición, y, sin embargo, ellos fueron maquillados de manera que aparecieran como vocablos quechuas atemporales y omnipresentes, es decir, invariables en el tiempo y en el espacio.

Ayar Auca. En cuanto al epíteto <Auca>, el guerrero, y mejor aún de $<$ Sauca $>$, "el alegre y feliz" (ver Garcilaso 1943;I, XVIII:47 [1609]), todo conduce a pensar que, en verdad, estamos ante un nombre de origen puquina, incorporado al vocabulario aimara, según evidencia proporcionada por Bertonio, quien recoge, por ejemplo, la frase <sauca pirca> "pared muy alta", es decir, grande (ver 1984;II:313), pero también <hauquipatha> "plaça grande" (Bertonio 1984;II:125), donde es lícito aislar el modificador $<$ hauqui $>$, fácilmente derivable de $<$ hauca $>$, y este, a su turno, relacionable con <sauca > (de allí también la confusión de Garcilaso entre $<$ sauca $>$ y $<$ hauca $>$, voces distintas 
en quechua). Como lo hemos demostrado en otro lugar, las variantes registradas por el ilustre aimarista son reacomodaciones de la voz puquina *hawkwa, "grande", conservada hasta hoy como préstamo en la variedad chipaya del uro (ver Cerrón-Palomino 2013b;V:\$3.1.2,185-186). De manera que, según esto, <Ayar Auca> vendría a ser "Ayar el grande", del mismo modo que la plaza mayor del Cuzco no sería sino "la plaza grande", y para mayor abundancia, la fiesta <aucay cuzqui>, "gran barbecho", del calendario inca estaría corroborando nuestra glosa, refrendada por su registro "traducido" al quechua como <hatun cuzqui $>$.

Ayar Uchu. Por lo que respecta a $<$ Ayar Uchu $>$, que Betanzos registra como < Ayaroche $>$ (ver 2015;I,III:5v [1551]), Cieza como < Ayar Ocho> (ver 1985; [VI]:13 [1551]), y Cobo en la forma de <Ayar Uche $>$ (ver Cobo 1956;LXII,III:62 [1653]), es decir bajo texturas formales diferentes a la canónica <uchu>, invitan a la sospecha de que estaríamos ante un nombre ajeno al quechua y al aimara. Indagando sobre ello, damos sobre el término uro <uzh>, es decir, /uș/ "niño, menor" (ver Cerrón-Palomino y Ballón Aguirre 2011:186), reconstruible como $* u \hat{c}(a)$, y con mucha probabilidad un préstamo del puquina en dicho idioma. De aceptarse esta hipótesis, $<$ Ayar Uchu> significaría entonces "Ayar el menor", en oposición a <Ayar Auca>, o sea "Ayar el mayor". La oposición no parece forzada desde el momento en que, en otros ámbitos del área andina, se ha continuado con la oposición entre por ejemplo $<$ Chauca churi $>$ "el hijo mayor" frente al $<$ Xullca churi> "hijo menor" entre los aillus coloniales de Cajatambo (ver Duviols 2003:764), oposición en la que el término puquina para "menor" no tuvo suerte como el relativo a "mayor", aunque no es descartable que sobreviva mediante uchuk o uchuy, que se han asumido como voces quechuas (en Áncash, se habría esperado utsuk y no uchuk, de haber sido vocablo patrimonial quechua).

Ayar Cachi. Por lo que toca al epíteto de $<$ Cachi $>$ no hay duda de que el término nada tiene que ver con su homófono quechua para "sal", y sí en cambio con el puquinismo $<$ cachi $>$ registrado por Bertonio como equivalente del quechua kallanqa, es decir, "cerco, aposento, corral" (ver 1984, II:32, 33 [1612]). En efecto, el radical <cachi>, que sobrevive en el aimara moderno kachi, está presente en la toponimia de todo el altiplano, descartando su interpretación como "sal", por razones de simple plausibilidad semántica (así en <Hacha-cachi> "cerco grande" o en $<$ Sopo-cachi $>$ "cerco de leña", que no resistirían una glosa con la noción de "sal"). Pues bien, queda sin embargo la motivación del apelativo < cachi $>$ en $<$ Ayar Cachi $>$, ya que a simple vista no parece haber ninguna. No obstante, la relectura de la saga de los Ayar parece sugerirnos una buena salida, y es que, según la leyenda, estamos hablando del hermano que, por recelos de los otros, es encerrado dentro de una cueva, es decir, en un cerco tapiado: el nombre estaría haciendo alusión, en forma simbólica, al Ayar cercado o tapiado. Para más información al respecto, ver Cerrón-Palomino (2013b, V:§ 3.1.2, 184-185).

\section{Epítetos y atributos privativos}

En esta sección nos ocuparemos de la etimología de tres "renombres", para emplear un término caro al Inca Garcilaso, que eran de uso privativo para referirse a los incas. Los epítetos seleccionados son $<$ capac $>$, <çapa $>$ y $<$ tupa $>$, que pasaremos a etimologizar seguidamente.

\section{Capac}

En cuanto a este nombre, creemos haber aportado suficiente evidencia para demostrar su procedencia puquina-colla (ver Cerrón-Palomino 2013a, I-2:§ 6.1.2, 72-73). En efecto, postulamos allí, tanto en forma como en significado, la protoforma *qhapaq, "poderoso", como su étimo respectivo. La mejor prueba de que no estamos ante una voz quechua ni menos aimara es el hecho de que no solo los jefes collas son mencionados como <colla capac $>$ en las fuentes cronísticas más tempranas (tal el caso, por ejemplo, de $<$ Chuchi Capac $>$ ), sino que, según testimonio proporcionado por Betanzos, eran ellos quienes se autodesignaban como <capac>, y habría sido el inca Pachacutiy quien, tras someterlos, dispuso que en adelante el mencionado apelativo fuera de uso real exclusivo. Nos lo dice taxativamente que

tenia pensado [Inca Yupanqui] quitar los nombres que cada señorçillo delos tales pueblos e prouinçias tenian de Capac. $E$ que no auia de auersi [sic] solo un Capac y que ese que lo hera el (ver Betanzos 2015, I, XVIII:41v; I, XXVII:69v; II, XXII:138 [1551] [énfasis mío]). 
La apropiación del término nobiliario, sin embargo, no parece haber tenido éxito, contra lo señalado por el Inca Garcilaso (ver 1943, I, XXVI:61 [1609]), y así han llegado a nosotros designaciones como las de $<$ Colli capac $>$ o $<$ Chimu capac $>$, referidas a los jefes étnicos respectivos sometidos por los incas que sucedieron a Pachacutiy. Para un desarrollo mayor acerca del tema, ver CerrónPalomino (2013a, I-4:§ 1).

\section{Çapa}

En cuanto a este modificador, nos dice el Inca Garcilaso que era un adjetivo atributivo de uso exclusivo en la fórmula mayestática de <Çapa Inca $>$, ya que esta designación significa

\section{Solo Rey o Solo Emperador o Solo Señor porque çapa quiere decir solo, y este nombre no lo daban a otro alguno de la parentela, ni aun al príncipe heredero, porque diciendo Rey solo, no podían dar su apellido a otro, que fuera ya hazer muchos Reyes (ver 1943, I:26, 60-61 [1609]).}

Ocurre, sin embargo, que al igual que en el caso de $<$ capac $>$, el jefe colla sometido por Pachacutiy, también se hacía llamar <capac çapa apo yndi chori>, "que dize Rey y solo señor hijo del sol y que hera muy poderoso y que tenia gran poder de gente" (ver Betanzos 2015, I, XX:9 [1551]). De hecho, para abundar en la materia no debe sorprender entonces que el señor de la provincia de Hatun Collao se llamara <Çapana $>$, "como otros que ovo deste nombre" (ver Cieza de León 1985:XLI, 121 [1551]), y que, de paso sea dicho, persiste hasta la actualidad como apellido en lo que fuera el antiguo territorio lupaca.

Pues bien, todos los historiadores, incluyendo a los pocos lingüistas que se ocuparon de él, asumimos hasta ahora que el adjetivo <çapa> era de origen quechua, más frecuentemente registrado como <çapa-lla>, es decir, sapa-lla (lit. "solito" o "único"), con variante $<$ hapa-lla $>$ en virtud del cambio antiguo $*_{s}>h$, en posición inicial de palabra, que define al quechua central (ver Parker 2013:§ 2.2 [1971]). No obstante ello, para algunos de nosotros la simple ocurrencia del mencionado adjetivo delante de $<$ Inca $>$ nos dejaba un sinsabor, pues su empleo en los dialectos quechuas ajenos al sureño, y más aún fuera del contexto cerrado de la fórmula mayestática, resultaba forzado, por no decir artificial; a diferencia de, por ejemplo, su empleo como pronombre flexionado (sapa-lla-y "yo solo", sapalla-yki "tú solo", etc.), que resulta natural y espontáneo. De esta manera, no solo el carácter inusitado de la expresión, sino también la sugerencia de que el adjetivo pudiera ser atributo propio de los colla-puquinas, según lo señalado por los cronistas citados, nos obligó a buscar otra etimología para $<$ Çapa $>$.

La pesquisa no se dejó esperar, pues allí estaba el vocabulario de Bertonio, en el que encontramos <sappa>, del que se nos dice que "es lo mismo que hisqui vel Maysana, vel Suti, Bueno o Sano" (ver 1984, I, II:309 [1612] [énfasis mío]). Si bien la voz ha desaparecido del aimara moderno, no es difícil restaurar la forma del adjetivo como sap'a, "bueno, sano", ya que el mismo Bertonio se apura en advertirnos que la voz debe escribirse dupplici $p p$ para diferenciarlo de <sapa>, "solo, único", obviamente tomado del quechua. Pues bien, si lo dicho vale para la forma, ¿qué hay con el significado? La respuesta nos la da el Inca Garcilaso, en sus disquisiciones más bien retóricas respecto del significado plurisémico de $<$ Capac $>$ y de $<$ Çapa $>$, al decirnos que el Inca era el magnánimo o "el principal bienhechor" de sus vasallos. Siguiendo este razonamiento, no hay duda de que incluso el "renombre" de $<$ Huacchacúyac $>$, que "quiere decir amador y bienhechor de pobres" (ver 1943, I, XXIV:57 [1609]), sea una traducción de <sappa> al quechua.

De esta manera, vemos cómo una palabra de origen puquina habría sido asociada, tanto en forma como en significado, a la voz quechua <sapa>. Una vez más, estaríamos ante un caso típico de etimología popular fomentada por los primeros quechuistas de la Colonia.

\section{$<$ Tupa>}

Referente a este epíteto, otro sobrenombre propio de la realeza incaica, nos refiere el quechuista cacereño que "dice cosa Real que toca al Rey" (ver Gonçález Holguín 1952: I, 347 [1608]) o que es un "nombre de honor para honrarle, o llamarle, o llamarse honrosamente, como nosotros dezimos Señor" (ver Gonçález Holguín 1952: I, 347 [1608]). En tal sentido, sin ir muy lejos, el nombre de $<$ Tupa Inca Yupanqui $>$ ilustra precisamente el empleo honorífico del epíteto; pero también los de <tupa 
cuca> "coca Real" o <tupa ñan> "camino Real" (ver Gonçález Holguín 1952: I, 347 [1608]). Más tarde, al adecuarse léxicamente el quechua como vehículo de evangelización, el adjetivo fue empleado para ensalzar a la máxima divinidad judeocristiana o a los apóstoles (así en <tupay Dios> o <tupay San Pedro $>$ ) o a las cosas sagradas de la liturgia cristiana (como en <tupa cocau> "sanctissimo sacramento"). De esta manera, la expresión difería, formando un par mínimo, del verbo <ttupa-> "afilar, alisar, limar" (ver Gonçález Holguín 1952, I:347 [1608]), también consignado por Bertonio como $<$ thupa-> "acepillar, limar, pulir", y mejor aún en su forma participial <thupa-ta $>$, <thupatahaque $>$ "hombre bien hecho, hermoso, proporcionado, \&" (ver 1984, II:368 [1612]). Pues bien, cotejando los datos del quechua con los del aimara, según los registran los lexicógrafos mencionados, tenemos que la forma <ttupa->, "afilar", del quechua se corresponde con la aimara $<$ thupa- $>$, o sea, /thupa-/, dejándonos <tupa $>$, es decir/tupa/, sin aspiración inicial, como el equivalente de "señor".

Ahora bien, como en los casos vistos anteriormente, la voz $<$ tupa $>$, de posible origen puquina (aunque no registrada por Bertonio), fue asociada por los quechuistas tardíos con la raíz <thupa->, que por su naturaleza verbal no se avenía como nombre, por lo que se la nominalizó como <tupac> "el que reluce, el reluciente", es decir, /tupa-q/, como lo encontramos en Garcilaso (ver 1943, VI, XXXIV:80 [1609]), habiendo devenido en la forma canónica, contraviniendo a la versión originaria del nombre, que por razones morfosemánticas no necesitaba de dicho sufijo, como nos lo demuestran los cronistas más tempranos, entre ellos Betanzos (ver 2015: <Topa Atau>, <Topa Ynga Yupangue>, <Tupa Cuxi Gualpa>, I, XX:48v; II, I:98v; II, XIII:115r [1551], respectivamente). Posteriormente, nuestros historiadores modernos, como por ejemplo Rowe (2003 [1985]), consumaron la quechuización anacrónica del término, reinterpretándolo como <thupaq $>$ (del mismo modo que se hizo con $<$ Pachacuti $>$, restaurado equívocamente como $<$ Pachacutec $>$ ). De esta manera, como se puede apreciar, un sobrenombre honorífico, de muy probable origen puquina, fue reinterpretado como quechua, habiendo sido relacionado, por pura etimología popular, con el vocablo nativo $<$ thupa- $>$, que después de todo se avenía, en forma y contenido, con el título nobiliario de <tupa >, "señor".

\section{Nombres de incas}

De la lista canónica de los gobernantes incas hemos elegido tres nombres cuya etimología discutiremos, a saber, $<$ Sinchi Roca $>$, $<$ Lloque Yupanqui $>$ y $<$ Yahuar Huacac $>$. De ellos, de acuerdo con su reinterpretación tradicional sesgada a partir del quechua, solo $<$ Roca $>$ constituiría un enigma, pues según el Inca Garcilaso no tendría "significación alguna, aunque en la particular de los Incas la tendrá" (ver 1943, II, XVI:99 [1609]). En lo que sigue veremos que, en verdad, los tres nombres han sido quechuizados a fortiori.

\section{(Sinchi) Roca}

Respecto de este nombre, dejando de lado el adjetivo <sinchi>, cuyo étimo remonta al protoaimara *sinci $i$, "recio, fuerte", hay que señalar, en primer lugar, que el sexto soberano cuzqueño también porta el apelativo de < (Inca) Roca $>$. En segundo lugar, notemos que Cieza de León registra este último nombre como < Ynga Roque > (ver 1985, XXXIV-XXV [1551]), sugiriéndonos una variante $<$ roque $>$, que por su persistencia no parece simple errata. En tercer lugar, hay indicios bastante sugestivos en el sentido de que dicho apelativo era de origen colla-puquina. Y así, por un lado, tenemos que el ya mencionado jefe colla $<$ Chuchi Capac $>$, también era conocido con el nombre de $<$ Ruqui Çapana $>$, según nos lo refiere Betanzos (ver 2015, I, XX:fol. 49r [1551]); y, por el otro, sabemos por un documento estudiado por Tristan Platt que hubo un embajador altiplánico ante la corte cuzqueña de Inca Yupanqui, llamado nada menos que <Loca Larama>, señor de Pocoata, de la etnia de los Charcas (ver Platt et al. 2006:723). En este caso, no hay duda de que $<$ loca $>$ no es sino variante de $<$ roca $>$, previa aimarización de la pronunciación (al aimara le repugnaba la /r/ inicial de toda palabra, como puede verse también en <larama> "azul profundo", proveniente del puquina $<$ rarama $>$ ). De esta manera tenemos ahora cuatro variantes de un mismo nombre: $<$ roca $>\sim<$ loca $>\sim<$ roque $>\sim$ $<$ ruqui $>$, las mismas que pueden reducirse a dos: $<$ roca $>$ y $<$ roque $>$.

Pues bien, llegados a este punto debemos señalar que aunque no es posible dar por ahora con el significado de la raíz, cuya forma arquetípica preferimos postular como <ruqi >, es decir, [roqe] (ver siguiente nombre), ya no queda duda de su origen 
ajeno al quechua y al aimara, pudiendo atribuirse, como Garcilaso, a la "lengua particular" de los incas, es decir, al puquina. Para más detalles acerca del tema, ver Cerrón-Palomino (2013a, I-3:§ 3.1.3).

\section{Lloque (Yupangui)}

En lo que respecta al tercer soberano dentro de la dinastía mítica, dejando de lado esta vez el nombre de linaje <Yupanqui>, que es un híbrido aimara-puquina, como creemos haberlo demostrado ampliamente en Cerrón-Palomino (2013a, I-4:§ 2), nos ocuparemos aquí solo del parcial $<$ Lloque $>$. Respecto de la etimología de este nombre nos dice el Inca Garcilaso que su significado "fue Lloque: quiere decir izquierdo; la falta que sus ayos tuvieron en criarle, por do salió çurdo, le dieron por nombre proprio" (ver 1943, II, XVII:101 [1609]). Como en muchos otros casos, el significado propuesto por el Inca llama a sospecha, de manera que no tenemos reparos en considerarlo como una muestra más de etimología fantasiosa dictada por la asociación gratuita que hace del nombre con la palabra quechua $<$ lloque $>$, es decir /lluq'i/. Por nuestra parte, quisiéramos proponer que $<$ lloque $>$ no sería sino una variante de $<$ roque $>$, y en prueba de ello llamamos la atención, como ya lo hemos venido haciendo (ver $\$ 3.2$ ), respecto de uno de los fenómenos fónicos sistemáticos atribuibles al puquina, con efectos sustratísticos en el quechua, consistente en la fluctuación $* r \sim l l$, como lo demuestran numerosos ejemplos del tipo < viru $\sim$ villu> "caña de maíz", <saru sallu > "piedra de cantera", $<$ Caravaya $\sim$ Callavaya $>$, etc. De esta manera, tanto $<$ roque $>$ como $<$ lloque $>$ vendrían a ser variantes de un nombre de linaje colla-puquina, postulable como *ruqi, y no un nombre singularizador como lo sostenía el Inca Garcilaso.

\section{Yahuar Huacac}

Finalmente, en relación con el significado de este nombre, la tradición histórica nos ha enseñado que quiere decir

el que llora sangre, y no lloro de sangre, como algunos interpretan; y el llorar fue cuando niño y no cuando hombre, ni por verse vencido y preso, como otros dizen, que nunca lo fue Ynca ninguno hasta el desdichado Huáscar (ver Inca Garcilaso 1943, IV, XVI:208 [1609]).
Se trata, como se ve, de una hermosa anécdota (ver Sarmiento de Gamboa 1965, [21]:226 [1572]), que no resiste el menor análisis. De paso, la leyenda del "llora sangre" ya la había recogido Betanzos (ver 2015, I, V:7v. [1551]), y tal vez el reproche va dirigido hacia él, aunque es Sarmiento quien efectivamente refiere que "Yaguar Guaca", [...] quiere decir "lloro de sangre" (1965, [21]:226 [1572]).

Pues bien, al respecto debemos señalar que hay por lo menos una fuente importante que nos ofrece una versión que se aparta de las ya vistas. Se trata de la proporcionada nada menos que por el licenciado Polo Ondegardo, gran escudriñador de antiguallas incaicas, quien, en su lista de los nombres de la dinastía inca, consigna el de $<$ Yahuarguaqui $>$, como el sucesor de < Ynca Roca $>$ (ver Polo Ondegardo 1985:fol.8 [1569]) ${ }^{1}$. Lo que puede sacarse en limpio del cotejo de las variantes vistas hasta aquí es el hecho de que la de Polo sea una versión reñida con las otras, tratándose de un nombre de capital importancia por la investidura de su portante. Descartamos, en tal sentido, que estemos ante un simple problema de escritura (o de edición), y más bien pensamos que se está ante una tradición recogida independientemente.

Ahora bien, teniendo en cuenta lo señalado, y descartando el significado anecdótico atribuido al nombre por razones de plausibilidad semántica, creemos estar en condiciones de sostener que <Yahuar Huacac> es un producto más del esfuerzo de los quechuistas (que bien podrían ser prehispánicos) por hacer inteligible un nombre que resultaba arcano para el común de los hablantes de la lengua. De esta manera, $<$ Yahuarguaqui> devino en <Yaguarguaca>, que es la forma en que la registran los cronistas más tempranos; posteriormente, los quechuistas letrados se encargarán de hacer que el significante se ajuste al significado, y para ello le agregarán al parcial $<$ guaca $>$, siguiendo un procedimiento muy socorrido, el sufijo agentivo que echaban de menos: <guaca-c>, es decir /waqa-q/ "el que llora".

\section{Nombres de instituciones}

Como ejemplos del léxico institucional incaico que han sido asumidos como originariamente quechuas, previa manipulación inconsciente o deliberada de los mismos, introduciremos aquí los casos de $<$ panaca $>$, y $<$ hatun runa $>$, términos propios de la organización sociopolítica y económica de los incas. 
En lo que sigue nos ocuparemos de su etimología ajena al quechua y al aimara.

\section{Panaca}

Por lo que respecta a este nombre, la única fuente temprana cuyo significado parece proporcionarnos es Sarmiento de Gamboa. En efecto, al narrar sobre la institucionalidad de las familias reales atribuida a Manco Capac, el cronista nos dice que este inca

hizo el primero ayllo y llamóle Chima PanacaAyllo, que quiere decir linaje que desciende de Chima; porque el primero a quien dejó encomendado su linaje o ayllo se llamó Chima y Panaca quiere decir descender (ver Sarmiento de Gamboa 1965;[14]:220 [énfasis mío]).

Sin embargo, tal parece que la etimología propuesta por Sarmiento no logró convencer ni al más eximio conocedor del quechua, entre ellos el Inca Garcilaso, ya que, en efecto, en esta lengua no solo no hay ningún verbo que se parezca al mencionado, sino que incluso la hechura en que fue consignado no se aviene con una forma infinitiva como la sugerida por la glosa castellana del cronista. Y así, nadie en adelante parece haberle prestado atención al dato, y es solo a comienzos del siglo XX cuando Uhle, uno de los fundadores de la arqueología andina, lanza la hipótesis según la cual "la palabra 'panaca' significa[ría] las hermanas" (ver Uhle 1969:15 [1911]). Esta hipótesis será no solo asumida sino reforzada por historiadores como Valcárcel (1925:37), Zuidema (1980;I:\$2,78) y Rostworowski (1983;cap. 6:138-145). Todos ellos coinciden con la propuesta del arqueólogo germano en el sentido de que < panaca> tendría como raíz básica la palabra quechua, en su forma sureña, pana "hermana de varón". Dicha interpretación, semánticamente sugerente, dio lugar a que se tejiera la tesis, tan cara a los historiadores modernos, del rol de la hermana del varón como el concepto fundamental en la organización social incaica, que de este modo habría sido de corte matrilineal. La explicación parecía contundente, aun cuando nadie podía explicar de manera convincente la naturaleza del remanente $<$ ca $>$ de $<$ panaca $>$, que no se avenía con ningún sufijo nominal quechua ni aimara.

Pues bien, en Cerrón-Palomino (2013a;I-3:§ 3.1.13), tras descartar la interpretación quechua en boga, postulamos una etimología aimara-puquina del término. Para ello recurrimos a la única fuente de la lengua colla-puquina que, aun cuando resulta escueta y limitada, no deja de proporcionarnos algunas sorpresas, como en el presente caso. $\mathrm{Y}$ es que la lengua registraba el verbo < paña- $>$ "caer, descender", verbo que recurre en los textos de Oré (ver Oré 1607:167, 401), y que bien podría ser el étimo buscado, ya que, además, semánticamente parecía estar en línea con la etimología de Sarmiento. Sin embargo, la nasal palatal (es decir/ñn) de este radical parecía ir en contra de la hipótesis sostenida; pero ocurre que nuestro primer lexicógrafo del quechua recoge precisamente la forma $<$ pañaca $>$ (ver Santo Tomás 1994;cap. XVIII:fol. 56v [1560]), es decir, con el radical idéntico al del puquina. Conjugados ambos radicales, solo quedaba por explicar entonces el remanente $<$ ca $>$.

Ahora bien, en el ensayo nuestro citado previamente, interpretábamos dicho remanente como el sufijo descensor aimara - $q a$, postulando finalmente *paña-qa como el étimo de <panaca>, siguiendo las reglas de derivación y lexicalización de la lengua altiplánica. Dicha explicación, si bien justificada en términos estrictamente lingüísticos, no excluye sin embargo otra alternativa de interpretación, esta vez a favor de una etimología quechua-puquina. Según esta, el verbo puquina paña-, tomado como préstamo por el quechua, habría sido nominalizado como paña-q "que cae, que desciende" (= "descendiente"). Esta forma, en boca de los aimara-hablantes, habría sido remodelada como pana-q(a), con la consabida vocal paragógica de naturaleza predecible en la lengua. Como se puede apreciar, ambas hipótesis postulan, desde el punto de vista del significante, en su manifestación superficial, una forma idéntica; sin embargo, bien evaluadas, y atendiendo a la glosa proporcionada por Sarmiento, parecería que la segunda alternativa se ajusta más a ella. Como quiera que fuese, de lo que no hay duda es que la palabra no tiene nada que ver con la voz quechua $<$ pana $>$, por lo que ya es tiempo de que los historiadores la descarten de su arsenal léxico.

\section{Hatun runa}

Por lo que respecta a esta expresión, definida por Gonçález Holguín como "Hombre basto, o labrador mitayoc o aldeano que no es de la ciudad" (ver Gonçález Holguín 1952;I:154 [1608]), donde $<$ hatun> es equivalente, según el mismo lexicógrafo, 
a "lo mayor, o mejor, o superior más principal o más conocido" (Gonçález Holguín 1952;I:154 [1608]), asombra constatar que en la frase el adjetivo meliorativo no solo no se vea reflejado en ella, sino que, paradójicamente, signifique todo lo contrario. ¿Cómo explicar semejante paradoja?

Pues bien, ocurre que aquí también, como en varios de los casos vistos anteriormente, se ha interpretado el radical verbal < hathu- $>$ "ocuparse, entender en algo", como en <yapuqui hathu->, "trabajar en alguna obra", registrado en el aimara (ver Bertonio 1984;II:124 [1612]), cual si fuera equivalente del quechua $<$ hatu(n) $>$, "grande". Como se puede ver, estamos aquí, en verdad, ante dos radicales diferentes no solo en cuanto a forma $(<$ hatu(n) $>$ y $<$ hathu- $>$ sino también en categoría gramatical (adjetivo en quechua y verbo en aimara). Desconocida la palabra en quechua y de uso restringido en aimara, todo hace sospechar que en este caso igualmente estamos ante una voz de origen puquina, apenas consignado por el aimara altiplánico colonial. No hay duda entonces de que la expresión $<$ hatun runa $>$ recogida por el jesuita cacereño debió haber sido algo como *hathu(n) runa "mitayo, trabajador, entendido en algo", pero que, al haber sido igualado $<$ hathu- $>$ con $<$ hatu-(n) $>$, dio lugar a que la frase entrara en la aparente contradicción que señalamos al principio. Es más, como lo ha demostrado Szemiñski, la denominación malinterpretada de < hatun runa > como "gente grande" dio lugar a que, en los relatos míticos concernientes a la edificación de Tiahuanaco, se diga que los alarifes de tales construcciones megalíticas habrían sido unos "gigantes", es decir <hatu(n) runa >, causando verdadero estupor entre los españoles, cuando los informantes nativos solo querían decir que eran obra de gente de oficio o especializada en la materia, o sea de $<$ hathu(n) runa $>$, mortales simples y comunes (ver Szemiñski 2003:324).

\section{Topónimos}

El registro de topónimos atribuibles al puquina no solo en el altiplano sino en el valle del Cuzco es un hecho patente que abona en favor de la tesis de la presencia de la lengua en dichos territorios, así como del contacto milenario entre sus pueblos. En esta sección postularemos la etimología puquina, total o parcial, de cinco topónimos, dos de ellos altiplánicos: $<$ Tiahuanaco $>$ y $<$ Copacabana $>$; y los tres restantes cuzqueños: $<$ Huanacauri $>,<$ Matagua $>$ $\mathrm{y}<$ Coricancha $>$.

\section{Tiahuanaco}

Por lo que respecta a este topónimo, intentaremos en esta oportunidad esclarecer el remanente $<$ huanaco $>$ del nombre, cuyo despeje habíamos dejado pendiente en nuestra disquisición previa acerca del tema (ver Cerrón-Palomino 2008;II-8:§ 5, nota 12). Para ello, conviene recordar, una vez más, que todas las etimologías propuestas desde la Colonia hasta la actualidad, al haber sido formuladas sin criterio filológico ni lingüístico alguno, como aquella que nos hiciera llegar el jesuita enciclopédico, no merecen tomarse en cuenta. De todos modos, por vía de anécdota, oigamos lo que Cobo cuenta cómo

\section{hallándose el Inca [en Tiahuanaco], le llegó un correo del Cuzco con extraordinaria brevedad, al cual [...], en llegando, le dijo: Tiay, guanacu, que en su lengua quiere decir: "Siéntate y descansa, guanaco". Diole nombre de guanaco, que es un animal de esta tierra muy ligero, por la brevedad con que había llegado, y ese nombre se le quedó al pueblo desde entonces, el cual pronunciamos nosotros mudadas algunas letras (ver Cobo 1956;XIII,XVIII:194-195 [1653]).}

Vemos como, una vez más, el topónimo es filtrado íntegramente por el quechua, cuya procedencia se da por descontada. Sin embargo, razones de simple plausibilidad semántica nos facultan a desechar el absurdo al mismo tiempo que nos obliga a buscar una interpretación más realista del nombre. Y así, en nuestra disquisición inicial referida, habíamos llegado a identificar el parcial $<$ tia $>$ con el adverbio $<$ thiya $>$ consignado por el jesuita anconense con la glosa de "lugar o parte muy lexos según la opinión de los hombres, el fin, o termino del mundo", tal como en el ejemplo <thiya marca>, "pueblo que está en los confines del mundo" (ver Bertonio, 1984;II:353 [1612]). No habiendo de otro lado bases para postular un étimo aimara para dicha partícula, lo más probable es que estemos ante una raíz de origen puquina. Quedaba, pues, por dilucidar el remanente $<$ huanaco $>^{2}$.

Pues bien, comencemos observando que dicho sobrante no puede ser una raíz irreductible por constar de más de dos sílabas, por lo que hay que ver en él un compuesto o una forma derivada, no importa de qué lengua andina se trate. En segundo lugar, 
descartamos una lectura a favor de $<$ huanacuk $>$ (es decir /wana-ku-q/) "el que se corrige y enmienda" (ver Gonçález Holguín 1952;I:177 [1608]), con caída predecible de $<\mathrm{k}>$, en razón de la procedencia geográfica y la antigüedad del nombre, indudablemente prequechua, y seguramente preaimara también. Descontadas estas lenguas, quedaría el puquina como la tercera entidad idiomática por consultar, y a ello nos abocaremos. Para empezar, conviene que descompongamos $<$ huanaco $>$ en $<$ huana $>$ y $<$ co $>$, y ello a raíz de que el elemento aislado $<$ huana $>$ recurre en topónimos y nombres propios tanto altiplánicos como cuzqueños, como lo hemos señalado en nuestra propuesta etimológica de <Xaquixaguana $>$ (ver Cerrón-Palomino 2013b;VIII:§3.4, 296-297). Pues bien, que esta raíz es de origen puquina nos lo confirma su registro en los textos de Oré como <vana>, "nuevo" (ver Oré 1607:109). Es más, el callahuaya la registra igualmente bajo la forma de <wani>, "flamante, nuevo" (ver Oblitas Poblete 1968:108; Guirault 1989;I:72). Pero esta misma lengua consigna también <wana>, "adorno" (ver Guirault 1989;I:72), que bien podría ser una variante no solo en significante sino también en significado. En consecuencia, es nuestra convicción que la evidencia toponímica, el registro documental, y el callahuaya, constituyen prueba sólida a favor del origen puquina del parcial $<$ huana $>$. Restaría entonces indagar respecto del elemento apendicular $<\mathrm{co}>$.

Para abordarlo, comencemos reconociendo que se trata de un remanente verdaderamente problemático. Hasta donde se puede conocer la gramática del puquina, no parece haber sido un sufijo, por lo que bien podría haberse tratado de un nombre, sobre todo si aceptamos que iba precedido de un modificador como <huana $>$. Pues bien, asumiendo el tipo de estructura nominal sugerido, quisiéramos postular, como una primicia, la raíz <coa> "divinidad/ santuario", de segura filiación puquina, según aparece bien documentada en Oré, con el significado sesgado de "ídolo" (ver Oré 1607:109), y que vendría a ser el núcleo de la frase respectiva. Por lo demás, el registro de dicha palabra no solo es de naturaleza documental sino que también está ampliamente atestiguado en la toponimia altiplánica (ver nombre siguiente), según lo señalamos en Cerrón-Palomino (2013b;VIII:\$3.4,296-297). Respaldados en dicha evidencia, proponemos la forma *wana-quwa "divinidad flamante" como el étimo de <huanaco $>$; y, en consecuencia, $<$ Tiahuanaco $>$ provendría de *thiya wana-quwa "la divinidad flamante del confín".
Queda por explicar, finalmente, la reducción de *quwa en $<$ co>, que, a falta de registro, solo cabe especular. Notemos, sin embargo, que dicha síncopa no es de ninguna manera forzada, sobre todo si postulamos el truncamiento de la vocal final: *wana-qowa $>$ wana-cow, con lo que todo se reduce a simple pronunciación y a su consiguiente traslado por escrito: <huanaco $>$.

\section{Copacabana}

En lo que concierne a este lugar sagrado de los incas, se ha querido ver en él una designación quechua, según la versión transmitida por el cronista del santuario del mismo nombre, quien refiere que

quiere decir [...] (lugar, y asiento donde se ve la piedra preciosa) porque Copa suena tanto como piedra preciosa, y cabana se deduze desta dicción kaguana que significa lo mismo, que Locus in quo videri poterit. Lugar donde se podrá ver. Juntas (pues agora) las dos dicciones, y acomodándolas a este dichossísimo lugar a boca llena, y con verdad le podemos llamar Copacabana, pueblo donde se puede ver la piedra (ver Ramos Gavilán 1988;I,XXXII:194, así como también II,II:214 [1621] [cursivas agregadas]).

Es decir, la etimología sería *qupa qhawana, donde el primer componente, o sea /qupa/, es el objeto del verbo, y significaría en principio "azul claro o turquesado" (ver Gonçález Holguín 1952;I:68 [1608]: <ccopa>; ver también Bertonio 1984;II:52 [1612]: <copa> "color verde"), y, por metonimia, aludiría a "turquesa"; y el segundo integrante del compuesto, analizable como /qhawa-na/, el verbo propio del quechua cuzqueño nominalizado, equivalente a "lugar donde se mira o donde es visible (el objeto)", tal como lo explica correctamente el cronista huamanguino.

Pues bien, creemos que basta situar el pasaje citado dentro del contexto de la obra para darnos cuenta de que estamos ante una interpretación que busca exorcizar el culto a la divinidad lacustre para reemplazarla por el de la virgen María, la "piedra preciosa" judeocristiana. En efecto, según narra el cronista, el lugar donde se erige el santuario a la virgen era el mismo en el que estaba el "Ídolo Copacabana", mirando al Sol, "como dando a 
entender que [la] deidad emanava del" (ver Ramos Gavilán 1988;I,XXXII:195 [1621]). En tal sentido, la asociación del nombre de la deidad local, presente también en el de <Copacati $>$ ("era de piedra con una figura malíssima, y todo ensortijado de culebras"), divinidad que estaba "a la salida del pueblo" de Yunguyo (ver Ramos Gavilán 1988;I,XXXII:196-197 [1621]), sería un caso más de etimología popular³ .

Ahora bien, como dejamos dicho en § 3.6.1, una de las divinidades lacustres más importantes era nombrado como $<$ coa $>$, designación que reinterpretamos como *quwa. Que este nombre sea mera variante de $<$ copa $>$ puede parecer escandaloso a quien desconoce una de las propiedades fónicas más recurrentes del puquina, consistente en la "lenición" o suavización de sus consonantes oclusivas, en este caso /p/, que podía realizarse como [b], alternando con $[\mathrm{w}]$, e incluso evaporarse completamente (ver Adelaar y van de Kerke 2009:\$2.1,129). Dicha conducta puede ilustrarse no solo con la frase <co pacas-na> $\sim<$ co huacas-na> "en esta tierra", entresacada de los textos de Oré (ver Oré 1607:400), sino también en las múltiples formas que adopta el elemento $<$ phaya > "cuesta", en la toponimia correspondiente a todo el territorio atribuible al puquina (ver CerrónPalomino 2013c:§4.1.1). No debe extrañar entonces que Torero, en su última versión del léxico puquina entresacado de Oré, haya propuesto tímidamente la ecuación <Quwa ¿copa? coa>, "ídolo, divinidad" (ver Torero 2004:5, §5.2, 453).

Tras la discusión efectuada hasta aquí, creemos que hay base suficiente como para postular el híbrido quechua-puquina *qupa qhawana, "el mirador del dios copa", que seguramente hacía alusión al lugar desde donde se podía divisar la "montaña sagrada" localizada en la isla del Sol, y en la que, según la tradición, se había posado el astro solar luego de la oscuridad de los siglos.

\section{Huanacauri}

En cuanto al famoso cerro desde cuya cima Manco Capac avistó el valle del Cuzco, y cuyo nombre, prácticamente ininteligible a los hablantes de quechua y aimara del siglo XVI, no podía dejar de ser igualmente objeto de interpretaciones absurdas a partir de la primera de estas lenguas. Sin embargo, una de las fuentes más tempranas parece proporcionarnos por lo menos el significado de la palabra. Nos dice, en efecto, al relatar la marcha del líder de los Ayar y su comitiva al Cuzco, que partiendo de [<Quirirmanta $>$ ], llegaron al cerro $[<$ Guanacauri $>$, que está dos leguas, poco más o menos, del asiento del Cuzco, y subidos a la cumbre, vieron en ella el arco iris del cielo, al cual los naturales llaman guanacauri. Y teniéndolo por buena señal, dijo Mango Capac: "Tened aquello por señal que no será el mundo más destruido por [falta de] agua" (ver Sarmiento de Gamboa 1965;[12]:216 [1572] [énfasis mío]).

Pues bien, caben aquí dos observaciones: primero, que la palabra no es quechua ni aimara; y segundo, por su carácter polisilábico, ella no puede ser un lexema simple. De manera que para los "naturales" de los que nos habla el cronista, seguramente quechua-hablantes ya, debía ser mero equivalente de "arco iris". Que ello era así, nos lo va a confirmar nada menos que Pachacuti Yamqui Salcamayhua, a quien preferimos citar in extenso a raíz del relato parecido al de Sarmiento. Dice, pues, el cronista indio de Canas, que Manco Capac

partió de allí [de <yaya carui>] al lugar donde la primera bes le había bisto aquel arco del cielo, llamado cuychi o turumanya o yayacarui y llegado allí a aquel lugar sentió de la falta de las compañías <de sus ermanos> y dijo: "probe de mí, desbenturado, sin padre y madre", y así biéndose así aflixido se esforçó echando de sí todas aquellas aflicciones y pesadumbres: "guaynacaptiy" o "guayna capriyllaypuni chica chiquicuna chayamouan", y desde entonces se llamó el lugar Guayna Caprii (ver Pachacuti 1993:fol. 7v [1613]).

Ahora bien, aun cuando la etimología formal de < guayna captiy> "cuando yo era joven" (es decir /wayna ka-pti-y/, que vendría a ser el lamento de Manco) resulta absurda en cuanto a motivación como nombre de lugar, hay que rescatar del pasaje la ecuación sémica que se establece entre $<$ yaya-carui $>$ y $<$ cuychi $>$ (o sea /k'uychi $>$ ) o $<$ turumanya $>$, voces estas últimas que significan "arco iris" en el quechua cuzqueño y en el central, respectivamente, pues no hace sino corroborar lo anotado por Sarmiento: no parece haber duda, pues, que el nombre hacía referencia al fenómeno atmosférico, augurio de una buena temporada de lluvias en el imaginario andino. 
De otro lado, hay que observar que, aun cuando el cronista indio sabía que el nombre "oficial" del cerro sagrado era <uanacaori>, según apostilla propia del autor al margen del pasaje del manuscrito, todo parece indicar que las variantes $<$ yaya carui $>$ $\mathrm{o}<$ guaynacaprii $>$ son aproximaciones formales deliberadamente introducidas por él con el objeto de encontrarles un ajuste con el significado plañidero que le atribuye. Como quiera que fuese, el hecho es que, al margen de su valor histórico real, tales variantes, en cuanto a su textura puramente formal, no resultan del todo descabelladas, como lo demostraremos en otro lugar.

Para terminar, y volviendo acerca de la palabra en estudio, creemos estar ahora en condiciones de postular el compuesto *wana kawri, "hermoso arco iris", como la etimología respectiva. Según se recordará, en \$3.6.1 dejamos identificado el adjetivo puquina <wana $>$, "hermoso, flamante, nuevo", de manera que solo quedaría en suspenso la naturaleza de la consonante inicial del sustantivo <cauri>, (que no sabríamos decir si sería /k/ o /q/), pero que interpretamos tentativamente como /kawri/, voz igualmente puquina cuyo significado sería el de "arco iris".

\section{Matagua}

Por lo que respecta a este paraje, siguiente al de Huanacauri en el itinerario emprendido por los Ayar en su marcha al Cuzco, hay que señalar que parece tratarse de un nombre íntegramente puquina, como el segundo, y no híbrido como $<$ Pallata>, "Dos cerros" (ver Cerrón-Palomino 2013a;I-2:§6.1.2) o <Yarambuy Cancha>, "Cerco de la cuesta de yaras", otros jalonamientos de la ruta mencionada.

Pues bien, notemos primeramente que la toponimia sureña peruana abunda en nombres terminados en $<$ gua $>$, como por ejemplo $<$ Andagua $>$ (Castilla, Arequipa) y $<$ Moquegua $>$, pero también en un etnónimo muy conocido como el de $<$ Collagua $>$, etc. En un trabajo anterior (ver Cerrón-Palomino 2008;II-3:\$2, nota 4) habíamos identificado dicha terminación como una modificación secuencial del sufijo ubicativo aimara -wi, pasando por $-w$ (con apócope vocálico), y posteriormente a - $w(a)$ (con vocal paragógica aimara). La propuesta, si bien algo compleja, se basaba en observaciones perfectamente naturales en contextos de bilingüismo quechua-aimara, de manera que $<$ Andagua $>$ (es decir, /anda-wa/) podía glosarse como "(Lugar) donde existe cobre". Sin embargo, gracias a la evidencia aportada por el más temprano registro del topónimo <Moquegua $>$, hoy estamos en condiciones de explicar de manera más convincente no solo la naturaleza del elemento <gua > sino, lo que es más importante, su incontrovertible procedencia puquina; hecho que, a su vez, permite esclarecer todos los topónimos de la región acabados en $<$ gua $>$.

En efecto, en el relato ofrecido por el autor de la Natural y general historia acerca de la marcha de Almagro en dirección del Cuzco, luego de su desastrosa expedición a Chile, refiere que

en los pueblos de Moquiguaya e Araguaya e Quinoaestaca e Umati e Saña, camino de la dicha Arequipa, [el Adelantado] tomó algunas lenguas, que apremiadas y apartadas unas de otras, discreparon en sus relaciones [acerca de la situación política tanto en Lima como en el Cuzco] (ver Fernández de Oviedo 1959;IX,VI:150 [1549]).

Tenemos al frente, como puede verse, lo que podríamos llamar el registro más enterizo de la variante del actual topónimo $<$ Moquegua $>$ y seguramente también el de <Aragua $>$, que sin embargo no aparece en los diccionarios geográficos (aunque es un yacimiento arqueológico importante en el Cuzco). Gracias a dicha documentación, sabemos ahora que $<$ Moquegua $>$ no solo es una versión sincopada de $<$ Moquiguaya $>$, sino que el topónimo es un compuesto en el que es posible separar los elementos $<$ moqui $>$ y $<$ guaya $>$, donde el segundo componente es el archiconocido elemento diagnóstico puquina a cuya manifestación polimórfica (phaya paya $\sim$ baya $\sim$ guaya $\sim$ huay, etc.; ver Cerrón-Palomino 2013c:§4.4.1) se agrega ahora <gua>, es decir, /wa/. Se trata, en efecto, de la forma más reducida y lenizada del sustantivo *phaya, "cuesta, subida", y que sufrió, además, por lo menos dos cambios muy regulares y sistemáticos debido a influencia aimara: waa (elisión de yod) y wa: (contracción vocálica en una sola vocal larga). De esta manera hay que suponer que formas evolucionadas como */muki-waa/, /anda-waa/ o /qulla-waa/, habrían sido registradas en castellano como $<$ Moquigua $>$, $<$ Andagua $>$ y $<$ Collagua $>$, respectivamente, pasando por el alto el alargamiento vocálico, no solo irrelevante en castellano sino también ajeno a su pronunciación y escritura. 
Pues bien, tenemos así allanado el camino para explicar el caso de $<$ Matagua $>$, cuya forma originaria, por simple inferencia, puede postularse como $*<$ Mata-guaya $>$ (es decir/mata-waya/). Si, de otro lado, puede identificarse $<$ mata $>$ como "raso" (ver Oré 1607:109), entonces el compuesto *mata waya habría significado "Cuesta Rasa".

\section{Coricancha}

Finalmente, en cuanto al famoso templo del Sol, y que se traduce como "Recinto de oro", todo conduce a pensar que estamos ante uno de los tantos casos de reajuste formal y semántico sobre la base de su interpretación quechua (/quri kancha/). En efecto, según se verá, no faltan indicios de orden lingüístico y documental que abonan en favor de lo señalado.

Comencemos recordando primeramente que, según la tradición recogida por los cronistas, habría sido Pachacutiy quien rebautiza el templo concernido, llamado previamente $<$ Inti Cancha $>$ "Recinto del Sol", como <Cori Cancha>. En segundo lugar, llama la atención que el cronista soldado, tan cuidadoso en sus averiguaciones, y según propia declaración conocedor del quechua (aunque seguramente incipiente), consignara de manera sistemática el nombre que nos ocupa en la forma de <Curi canche> (ver Cieza de León 1984;xcii:258 [1553]; 1985;li:147 [1551]). Lo interesante de este registro, que no nos parece simple cacografía, es su tratamiento vocálico, diferente del de la versión tradicional.

Pues bien, por lo que respecta al segundo elemento del nombre compuesto, es decir <canche>, ya habíamos adelantado la sospecha de que bien podríamos estar ante la voz puquina ligeramente distorsionada de <kachi $>$, "cerco, aposento" (ver Cerrón-Palomino 2013a;I-2:§6.2, nota 42). Un dato de orden mitohistórico que abonaría en favor de esta posibilidad sería el hecho de que, según información recogida por el cronista mercedario, habría sido el jefe colla Chuchi Capac, puquinahablante, quien

acabó la casa y templo del sol y dotóle, dándole toda la tierra que había conquistado lo más precioso y rico que en ella poseía, y así de ganados, chacaras, criados, mujeres y servicio (ver Murúa 1987;I,XX:77 [1613] [énfasis mío]).
En cuanto al segundo componente del compuesto, es decir <curi>, igualmente llama la atención que Cieza no lo registre como <cori>, que es la notación generalizada de los cronistas y lexicógrafos cuando consignan por escrito la palabra quechua equivalente a "oro". Este hecho le hace sospechar a Szemiñski, y esta vez con razón, que en verdad estaríamos ante la voz <curi> "trueno, relámpago", es decir, /kuri/, y no ante /quri/ "oro". (ver Szemiñski 1997:149-150). Se trataría, pues, del equivalente del quechua <illa-pa>, según se desprende del pasaje de Guamán Poma en el que, hablando del sistema de creencias mágico-religiosas de los indios, refiere que "quando nasen dos crias de un vientre $[\ldots]$ o sale de los pies [...] dizen ques hijo de yllapa y de curi" (ver Guamán Poma 1936:276 [1615]). Esta creencia era naturalmente combatida en el contexto de la extirpación de idolatrías, llegando a prohibirse que los indios portaran nombres como los mencionados, según se desprende de uno de los edictos consignados por Arriaga, y que a la letra dice

Item si saben que alguna o algunas personas ya grandes y donde estén por baptizar o los ya baptizados se llaman con nombres de las huacas o del trueno, llamándose Curi, o del Rayo llamándose Libiac (ver Arriaga 1999:No. 9, 172 [1621]).

No debe extrañar entonces que <curi $>$ no aparezca en los registros lexicográficos, aunque de su existencia en algunos dialectos quechuas nos da testimonio la variedad central de Pacaraos (Huaral), confirmándonos la naturaleza de su significante y significado: /kuri/ (ver Adelaar 1982). Ocurre, sin embargo, que el término no es quechua ni aimara, por lo que debe tratarse, con toda probabilidad, de una voz de origen puquina. De aceptarse esta hipótesis, entonces tendríamos allanado el camino para postular *kuri kachi "Recinto del trueno", con remodelación quechua total, deliberada o espontánea, como $<$ Cori cancha $>$.

Que no es nada forzada la interpretación del nombre nos lo prueba el hecho de que el templo albergaba, al lado de la del Sol, la estatua del Trueno, según nos lo refiere el cronista enciclopédico, quien sin embargo ya no menciona el término que nos interesa, no obstante enumerar tres nombres para la misma divinidad. Dice, pues, el cronista que los indios 
Llamaban al trueno con tres nombres: el primero y principal era chuqui illa, que significa resplandor de oro; el segundo catu illa, y el tercero, inti illapa. De cada nombre destos hicieron una estatua de mantas de la misma forma que las del sol, porque decían que el trueno tenía hijo y hermano [...] Estaban colocadas estas estatuas en el templo del sol, cada una en su altar (ver Cobo 1956;XII,VII:160 [1653]).

De esta manera, respondiendo la pregunta que Szemiñski se formulaba sobre si $<$ Cori Cancha $>$ era originariamente /Kuri kancha/, diremos que sí, en cuanto al primer componente del compuesto, pero que respecto del segundo preferimos interpretarlo como /kachi/. En ambos casos estaríamos, pues, ante una designación íntegramente puquina, lo que no debía sorprender en vista de los datos etnohistóricos aportados.

\section{Conclusiones e implicancias generales}

1. El examen filológico de tales nombres demuestra que ellos han sido distorsionados, las más de las veces de manera deliberada, para ser interpretados a partir del quechua.
2. ¿Qué significa que casi la totalidad de tales nombres, una vez restituidos, sean de origen puquina? No se trata de un registro esporádico y accidental ni menos artificial.

3. Tampoco se trata de un vocabulario propio del "lenguaje ordinario", sino de un sistema léxico perteneciente al universo ideológico-cultural, religioso, sociopolítico y espacial del imperio incaico.

4. Es forzoso concluir entonces que el registro de tales nombres demuestra que el puquina cumplió un rol importante y decisivo en la génesis y el desarrollo de la sociedad incaica.

5. La existencia de dicho registro constituye un desafío para los historiadores y arqueólogos, quienes están llamados a interpretar, en términos sociopolíticos y culturales, lo que sugiere dicha impronta léxica.

6. La premisa metodológica derivada de ello es que, al abordar la etimología del léxico primigenio, por no decir fundacional (institucional y cultural) del incario, deben abandonarse de una vez por todas las tentaciones de su interpretación exclusivamente quechua.

7. No es exagerado sostener entonces que de todo ello surge la necesidad de reescribir la historia incaica, interpretada hasta hoy por medio del lente exclusivo del quechuismo primitivo.

\section{Referencias Citadas}

Adelaar, W.F.H.

1982 Léxico del quechua de Pacaraos. Documento de Trabajo $\mathrm{N}^{\circ}$ 45. Instituto de Investigaciones de Lingüística Aplicada (CILA), Universidad Nacional Mayor de San Marcos, Lima, Perú.

Adelaar, W.F.H. y S. van de Kerke

2009 Puquina. En Lenguas de Bolivia. Tomo I: Ámbito andino, editado por Mily Crevels y Pieter Muysken, p. 125-146. Musef y Plural, La Paz, Bolivia.

Arriaga, P.J. de

1999 [1621] La extirpación de la idolatría en el Pirú. Centro de Estudios Regionales Andinos "Bartolomé de las Casas", Cuzco, Perú.

Bertonio, L.

1984 [1612] Vocabvlario de la lengua aymara. Ceres e Instituto Francés de Estudios Andinos, Cochabamba, Perú.

Betanzos, J.D. de

2015 [1551] Suma y narración de los incas, editado por Francisco Hernández y Rodolfo Cerrón-Palomino. Fondo Editorial de la Pontificia Universidad Católica del Perú, Lima, Perú.

Cabello Valboa, $M$.

1951 [1586] Miscelánea antártica. Instituto de Etnología, Universidad Nacional Mayor de San Marcos, Lima.
Cerrón-Palomino, R.

2000 Lingüística aimara. Centro de Estudios Regionales Andinos "Bartolomé de las Casas", Cuzco, Perú.

Cerrón-Palomino, R.

2003 Castellano andino (estudios sociolingüísticos, pedagógicos y gramaticales). Fondo Editorial de la Pontificia Universidad Católica del Perú, Lima, Perú.

Cerrón-Palomino, R.

2013a Las lenguas de los incas: el puquina, el aimara y el quechua. Peter Lang, Frankfurt am Main, Alemania.

Cerrón-Palomino, R.

2013b Tras las huellas del Inca Garcilaso: el lenguaje como hermenéutica en la comprensión del pasado. Latinoamericana Ediciones, Boston, Estados Unidos.

Cerrón-Palomino, R.

2014 En pos del puquina: la tercera lengua general del antiguo Perú. En III Encuentro de Lenguas Indígenas Americanas, editado por M. Malvestiti y P. Dreidemie, pp. 143-157. Universidad Nacional de Río Negro, Río Negro, Argentina.

Cerrón-Palomino, R. y E. Ballón Aguirre

2011 Chipaya. Léxico y etnotaxonomía. Fondo Editorial de la Pontificia Universidad Católica del Perú, Lima, Perú.

Cieza de León, P. de

1984 [1553] Crónica del Perú, Primera Parte. Fondo Editorial de la Pontificia Universidad Católica del Perú, Lima, Perú. 
Cieza de León, P.

1985 [1551] Crónica del Perú, Segunda Parte. Fondo Editorial de la Pontificia Universidad Católica del Perú, Lima, Perú.

Cobo, B

1956 [1653] Historia del Nuevo Mundo. Obras del P. Bernabé Cobo, Tomos I-II. BAE, Ediciones Atlas, Madrid, España.

Croese Nijssen, R.

1989 Evidencias léxicas y gramaticales para una posible filiación del mapudungun con la familia arawak. En Temas de Lingüística Amerindia, editado por R. Cerrón-Palomino y G. Solís Fonseca, pp. 275-290. Actas del Primer Congreso Nacional de Investigaciones Lingüístico-Filológicas, Concytec/ GTZ, Lima.

D'Altroy, T.N.

2015 The Incas. Wiley Blackwell, UK.

De la Grasserie, R.

1894 Langue Puquina. K.F. Koehler, Libraire-éditeur, Leipzig, Alemania.

Duviols, $\mathrm{P}$

2003 Procesos y visitas de idolatrías. Cajatambo, siglo XVII. Instituto Francés de Estudios Andinos y Fondo Editorial de la Pontificia Universidad Católica del Perú, Lima, Perú.

Eliade, $\mathrm{M}$.

2000 Tratado de Historia de las Religiones. Ediciones Cristiandad, S.A., Madrid, España.

Fernández de Oviedo, G.

1959 [1549] Historia general y natural de las Indias, CXXI, Tomo V. BAE, Madrid, España.

Garcilaso de la Vega, I.

1943 [1609] Comentarios Reales de los Incas. Emecé Editores S.A., Buenos Aires, Argentina.

Girault, L.

1989 Kallawaya: el idioma secreto de los incas. Unicef, OPS y OMS, La Paz, Bolivia.

Gonçález Holguín, D.

1952 [1608] Vocabvlario de la lengva general de todo el Perv llamada lengva qquichua o del Inca. Universidad Nacional Mayor de San Marcos, Lima, Perú.

Guamán Poma de Ayala, F.

1936 [1615] Nueva corónica y buen gobierno. Institut d'Ethnologie, París, Francia.

Hardman de Bautista, M.J.

1975 [1966] El jaqaru, el kawki y el aymara. Actas del Simposio de Montevideo, p. 186-192. Editorial Galache, México D.F., México.

Molina, C. de

2010 [1573] Relación de las fábulas y ritos de los incas, editado por P. Jiménez del Campo. Iberoamericana y Vervuert, Madrid, España.

Montesinos, F. de

2009 [1585] Un ejemplo de larga tradición histórica andina. Libro $2^{\circ}$ de las Memorias antiguas historiales y políticas del Pirú, editado y comentado por I. Szsemiñski. Iberoamericana y Vervuert, Madrid, España.

Murúa, M. de

1987 [1613] Historia general del Perú. Historia 16, Madrid, España.

Oblitas Poblete, E.

1968 El idioma secreto de los incas. Editorial "Los Amigos del Libro", La Paz, Bolivia.
Oré, J. de

1607 Ritvale sev Manvuale Pervanvm [...]. Jacobum Carlinum et Constantinum Vitalem, Neapoli.

Pachacuti, J. de S.C.

1993 [1613] Relación de antigüedades deste reyno del Piru. Estudio etnohistórico y lingüístico de Pierre Duviols y César Itier. Instituto Francés de Estudios Andinos y Centro de Estudios Regionales Andinos "Bartolomé de las Casas”, Cuzco, Perú.

Parker, G.J.

2013 [1971] La evolución del Quechua B. En Trabajos de lingüística histórica, traducido, editado y con notas de R. Cerrón-Palomino, pp. 197-257. Fondo Editorial de la Pontificia Universidad Católica del Perú, Lima, Perú.

Pärssinen, M.

2003b Tawantinsuyu: el estado inca y su organización política. Instituto Francés de Estudios Andinos y Fondo Editorial de la Pontificia Universidad Católica del Perú, Lima, Perú.

Platt, T., T. Bouysse-Cassagne y O. Harris

2006 Qaraqara-Charka. Mallku, Inka y Rey en la provincia de Charcas (siglos XV-XVII). Instituto Francés de Estudios Andinos y Plural, La Paz, Bolivia.

Polo Ondegardo, J.

1985 [1584-1585] Tratado de los errores y svpersticiones delos Yndios. Confessionario para los cvras de indios. pp. 265-283. Consejo Superior de Investigaciones Científicas, Madrid, España.

Ramos Gavilán, A.

1988 [1621] Historia del Santuario de Nuestra Señora de Copacabana. Edición de Ignacio Prado Pastor, Lima, Perú.

Ricoeur, P.

1986 Retórica, poética y hermenéutica. En Horizontes del relato. Lecturas y conversaciones con Paul Ricoeur, editado por G. Aranzueque. Cuaderno Gris, Madrid, España.

Riva Agüero, J. de la

1966 [1930] Razas y lenguas probables de la civilización de Tiahuanaco. Obras Completas, Tomo V, pp. 115-170. Pontificia Universidad Católica del Perú, Lima, Perú.

Rostworowski, M.

1983 Estructuras andinas del poder. Ideología religiosa y política. Instituto de Estudios Peruanos, Lima, Perú.

Rostworowski, M.

1993 Los ayarmaca. Ensayos de Historia Andina, pp. 241280. Instituto de Estudios Peruanos y Banco Central de Reserva del Perú, Lima, Perú.

Rowe, J.H.

2003 [1985] La constitución inca del Cuzco. En Los incas del Cuzco. Siglos XVI-XVII-XVIII, editado por J. Flores Ochoa, pp. 45-78. Instituto Nacional de Cultura, Cuzco, Perú.

Santo Tomás, D. de

1994 [1560] Grammatica de la lengua general del Peru. Edición facsimilar, transliteración y estudio preliminar de Rodolfo Cerrón-Palomino. Ediciones de Cultura Hispánica, Madrid, España.

Sarmiento de Gamboa, P.

1960 [1572] Historia Indica, Tomo CXXXV, pp. 195-279. BAE, Ediciones Atlas, Madrid, España.

Szemiñski, J.

1997 De las vidas del inka Manqu Qhapaq. Fundación Xavier de Salas, Convento de la Coria, Cáceres, España.

Szemiñski, J.

2003 Acerca de las posibilidades de encontrar huellas de una larga tradición histórica en las fuentes del siglo XVI y 
XVII. En Los Andes: cincuenta años después (1953-2003). Homenaje a John Murra, editado por A. M. Lorandi, C. Salazar-Soler, N. Wachtel, p. 317-337. Fondo Editorial de la Pontificia Universidad Católica del Perú, Lima, Perú.

Torero, A.

1964 Los dialectos quechuas. Anales Científicos de la Universidad Agraria, 2: 446-478.

Torero, A.

1972 [1970] Lingüística e historia de la sociedad andina. En El reto del multilingüismo en el Perú, compilado por Alberto Escobar, pp. 51-106. Instituto de Estudios Peruanos, Lima, Perú.

Torero, A.

1987 Lenguas y pueblos altiplánicos en torno al siglo XVI. Revista Andina, 10: 329-405 (con debate).

Torero, A.

2004 Idiomas de los Andes. Lingüística e Historia. Instituto Francés de Estudios Andinos, Editorial Horizonte, Lima, Perú.
Urbano, $\mathrm{H}$.

1981 Wiracocha y Ayar. Héroes y funciones en las sociedades andinas. Centro de Estudios Regionales Andinos "Bartolomé de Las Casas", Cuzco, Perú.

Uhle, $\mathrm{M}$.

1969 [1910] Los orígenes de los incas. En Estudios de Historia Incaica, pp. 29-69. Universidad Nacional Mayor de San Marcos, Lima, Perú.

Urton, G.

2004 Historia de un mito: Pacaritambo y el origen de los inkas. Centro de Estudios Regionales Andinos "Bartolomé de Las Casas", Cuzco, Perú.

Valcárcel, L.E.

1925 Del ayllu al imperio. Editorial Garcilaso, Lima, Perú. Zuidema, T.R.

1980 El parentesco inca: una nueva visión teórica. Reyes y guerreros. Ensayos de cultura andina, pp. 54-116. Fomciencias, Lima, Perú.

\section{Notas}

1 Otra fuente, si bien polémica, que igualmente parece proporcionarnos una variante diferente de las vistas hasta aquí es Montesinos, para quien el nombre habría sido < Yaguarhuquiz> (ver Montesinos 2009: cap. 12, \$4.9.1, 172 [1585]). Sin embargo, descartamos el dato, y no solo por su naturaleza cacográfica, desde el momento en que pensamos que el fantasioso autor está confundiendo el nombre del inca, a quien el editor llama "papa Gregorio peruano", con el del mes de junio, según el calendario ofrecido por Molina: <chahuarhuay>, seguido del nombre <quiz>, "mes" (ver Molina 2010:fol. 10r [1573]).

2 Descartamos aquí toda asociación del nombre del camélido andino con este remanente del topónimo, pura coincidencia causante de la etimología popular que acabamos de citar. En otro lugar ofrecemos el posible origen onomatopéyico de aquel (ver Cerrón-Palomino 2003; VI: § 3.1).

3 No así, sin embargo, en el topónimo <Copayapu>, "tierra de turquesas"), y no "tierra de olleros", como pensaba Torero motivado por la pronunciación moderna del nombre, es decir, Copiapó (ver Torero 1987:403), provincia que estuvo representada dentro de las cuarenta y dos "naciones" con que Tupa Inca Yupanqui repobló Copacabana (ver Ramos Gavilán 1988; I,XII:85 [1621]). 
